\title{
O papel do conflito na teoria crítica contemporânea em Axel Honneth
}

\author{
The role of conflict in contemporary critical theory in Axel Honneth
}

\author{
ARAÚJO NETO, José Aldo Camurça. Doutor/Licenciado em Filosofia \\ Instituto Federal de Educação, Ciência e Tecnologia do Sertão Pernambucano - Campus Serra Talhada. Rodovia \\ PE 320, KM 126, Zona Rural Caixa Postal 78 | Serra Talhada/PE - Brasil / Telefone: (87) 98866-1978 / E-mail: \\ jose.aldo@ifsertao-pe.edu.br
}

\begin{abstract}
RESUMO
Experiências de desrespeito estão dentre os conflitos que traduzem uma quebra de expectativas normativas presentes na base da sociedade e que, por conseguinte, podem converter-se em luta por reconhecimento. Esta última é apresentada por Axel Honneth (1949-) como a gramática moral dos conflitos sociais, sendo estes entendidos como bases da interação social. 0 tema do conflito em Honneth é situado a partir de sua teoria crítica configurada como filosofia social e está vinculado estreitamente a já mencionada violação das condições de reconhecimento que incide sobre a identidade do sujeito e a sua capacidade de autorrealização. Diante desta análise, o presente artigo objetiva analisar os impactos do conflito humano na filosofia do reconhecimento em Axel Honneth. Tal análise vai partir dos momentos de reconhecimento e os de não reconhecimento (desrespeito) apresentados pelo autor frankfurtiano em sua teoria política.
\end{abstract}

Palavras-chave: conflito, reconhecimento, desrespeito.

\begin{abstract}
Disrespectful experiences are among the conflicts that translate a breach of normative expectations present at the base of society and, therefore, can become a struggle for recognition. The latter is presented by Axel Honneth (1949-) as the moral grammar of social conflicts, which are understood as the basis for social interaction. The conflict theme in Honneth is based on his critical theory configured as social philosophy and is closely linked to the aforementioned violation of the conditions of recognition that affects the identity of the subject and his capacity for self-realization. Given this analysis, this article aims to analyze the impacts of human conflict on the philosophy of recognition in Axel Honneth. Such analysis will start from the moments of recognition and those of non-recognition (disrespect) presented by the Frankfurt author in his political theory.
\end{abstract}

Keywords: conflict, recognition, disrespect.

\section{1- Introdução}

Experiências de desrespeito estão dentre os conflitos que traduzem uma quebra de expectativas normativas presentes na base da sociedade e que, por conseguinte, podem converter-se em luta por reconhecimento. Esta última é apresentada por Axel Honneth (1949-) como a gramática moral dos conflitos sociais, sendo estes entendidos como bases da interação social. A propósito, vale salientar que é justamente nesse aspecto que o modelo de teoria crítica de Honneth (2006) procura distinguir-se do modelo habermasiano. ${ }^{1}$

\footnotetext{
${ }^{1}$ Honneth se insere na tradição que remonta aos autores tanto do círculo interno quanto externo do Instituto de Pesquisa Social, bem como a Habermas, que interpretam a situação social própria às sociedades capitalistas contemporâneas como um "estado de negatividade social", portador de patologias sociais. Para Honneth (2006),
} 
Em vez de enveredar pelo caminho de uma teoria da ação comunicativa baseada numa pragmática formal da linguagem, Honneth opta por um modelo de teoria crítica que toma como âncora uma gramática moral dos conflitos sociais. A ênfase não será atribuída ao consenso, compreendido como telos da interação, mas ao conflito. Na teoria da sociedade de Habermas (2006), a dimensão do conflito teria ficado em segundo plano, de modo que Honneth critica a intersubjetividade orientada para o entendimento e volta-se para a dimensão das experiências de desrespeito. A teoria de Habermas padeceria de um déficit sociológico, pois lhe faltaria tematizar os fundamentos normativos da crítica a partir da dinâmica social dos inseridos nela. Tais fundamentos poderiam ser encontrados nas experiências de injustiça e de humilhação e nos conflitos que resultam delas.

Apesar desta argumentação, o objetivo central deste artigo não vai se limitar em apontar os erros cometidos por Habermas na questão do conflito. Mesmo porque Honneth não pretende seguir o mesmo caminho trilhado por ele. Ou seja, ao invés de se deter na tensão entre sistema e mundo da vida, como fizera Habermas, a teoria crítica deveria voltar-se para as causas da violação das condições de reconhecimento. Numa palavra, tais violações são representadas ("simbolizadas") a partir das patologias sociais.

O tema do conflito em Honneth é situado a partir de sua teoria crítica configurada como filosofia social e está vinculado estreitamente a já mencionada violação das condições de reconhecimento que incide sobre a identidade do sujeito e a sua capacidade de autorrealização. É justamente esse risco de violação ou de lesão das condições intersubjetivas pressupostas na forma da autoconfiança, do autorrespeito e da autoestima que impulsiona a busca por reconhecimento. Portanto, trata-se de mostrar que a ideia de formação mediante o reconhecimento tem como base e mola propulsora o conceito de conflito.

Para tanto, o artigo seguirá os seguintes passos: as considerações a serem pressupostas sobre o tema e a questão da formação. Tais elementos ajudam-nos a explicar os reais motivos do aparecimento desse debate na teoria do reconhecimento em Axel Honneth. Dito de outro modo, a questão do conflito se manifesta a partir do momento em que as pautas políticas dos grupos minoritários almejam uma pretensão de efetividade, de concretização de seus objetivos. Apesar de tais demandas não adquirirem simpatia, consenso inicial do chamado "grande público", as questões implícitas que elas trazem ajudam no aperfeiçoamento dos mecanismos de participação política. Honneth, nesse sentido, percebe essas contribuições das minorias atuais discutindo essa problemática do conflito em sua filosofia.

\section{2 - Considerações introdutórias ao assunto}

O tema do conflito em Honneth se manifesta a partir destas cinco considerações. A primeira delas enxerga nas esferas relacionais de reconhecimento modos distintos de se aplicar um princípio universal de intersubjetividade. A segunda consideração, refere-se às experiências de desrespeito que afetam a identidade dos sujeitos propiciando um reconhecimento degenerativo, ou seja, negativo. Já

assim como para os diferentes representantes da teoria crítica, é justamente a falta de racionalidade social o fator que causa as patologias da sociedade capitalista. 
a terceira consideração trata-se interpretação das lutas sociais a partir de experiências morais. A quarta consideração trata das reações emocionais negativas assumirem uma importância fundamental para impulsionar a luta por reconhecimento. Por fim, a quinta consideração é a tese de que o estabelecimento de uma relação positiva consigo mesmo associa-se à capacidade do sujeito ser reconhecido como pessoa de valor. Cada uma destas análises é defendida por Honneth em seus escritos de filosofia política.

A primeira dessas considerações distingue cada conflito interno ao princípio universal de reconhecimento. Esses princípios são respectivamente: a relação afetiva entre mãe e filho, a adjudicação de direitos e a solidariedade a nível coletiva. À luz de cada um desses princípios, o sujeito pode expressar, quando for o caso, experiências concretas de desrespeito e, por essa via, colocar as bases para a ampliação do reconhecimento em cada uma de suas três esferas (HONNETH, 2003, p. 144-145).

$\mathrm{Na}$ esfera das relações afetivas, o conflito interno visa a colocar necessidades recémdesenvolvidas ou que ainda não foram levadas em conta. Apela-se, nesse caso, ao amor mutuamente testemunhado entre mãe e filho, com a finalidade de obter um tipo de atenção diferente ou mais amplo do que até então tivera ${ }^{2}$. Na esfera do direito, o conflito está baseado na ideia de igualdade e visa a mostrar que os grupos antes excluídos merecem ser legalmente reconhecidos. Na esfera social, o conflito leva os indivíduos ou os grupos a promoverem atividades e capacidades que até então eram descuidadas ou subvalorizadas. A finalidade do conflito, aqui, é exigir tanto uma estima social maior quanto uma justa redistribuição de recursos materiais.

A segunda consideração, por sua vez, trata do seguinte: o tipo de conflito que interessa a Honneth é aquele originado por experiências de desrespeito que afetam a identidade dos sujeitos, o reconhecimento denegado. Em razão de o conflito ser entendido como expressão própria de experiências morais que emanam da lesão de expectativas de reconhecimento profundamente arraigadas, a pretensão de Honneth é formular uma teoria social de teor normativo, vinculando um conceito de luta que parta de sentimentos morais de injustiça. 0 seu foco são as experiências morais associadas aos processos de negação do reconhecimento para indicar como o conflito pode traduzirse na forma de luta por reconhecimento, a qual vincula uma força moral capaz de impulsionar o sujeito à ação. Sua concepção de conflito não deve ser concebida, no entanto, apenas mediante um quadro explicativo acerca do surgimento de lutas sociais, mas, principalmente, a partir do caráter normativo de uma luta moral. Esse sentido moral da luta está associado à pretensão mútua dos indivíduos de que a sua identidade seja reconhecida pelos outros.

Essa pretensão é inerente à vida social, concebida como tensão normativa que leva a conflitos morais entre sujeitos que dependem socialmente uns dos outros. A luta desencadeada entre os sujeitos é um acontecimento moral e é constituída com relação à meta do reconhecimento intersubjetivo. A luta por reconhecimento é o meio de ação social pelo qual a relação entre os sujeitos pode adquirir gradativamente uma forma moral mais ambiciosa e, desse modo, levar a níveis mais desenvolvidos da relação social, viabilizando um crescimento tanto da socialização quanto da

\footnotetext{
${ }^{2}$ Honneth corrige, em Redistribution or recognition? (2003a, p. 144), algo que defendia em 1992, em Luta por reconhecimento (2003, p. 276), a saber, que o amor não admitia potencial para o desenvolvimento normativo.
} 
individuação.

A terceira consideração se refere à interpretação das lutas sociais a partir de experiências morais, não ficar pré-determinado por quais meios práticos as experiências de desrespeito podem ser superadas; se, por exemplo, por força material ou simbólica. ${ }^{3} 0$ ponto central desta terceira consideração reside em como articular as expectativas privadas dos indivíduos em relação ao desrespeito sofrido e às finalidades impessoais do movimento social. Entre ambas, precisa haver uma ponte semântica que deve permitir a construção de uma identidade coletiva. Por conseguinte, somente quando o sentimento de desrespeito se converter em base motivacional de resistência coletiva, articulado num quadro de interpretação intersubjetivo, é que o conflito pode transformarse em mola propulsora para a luta por reconhecimento. Quando convertidos em luta por reconhecimento, conflitos oriundos de experiências de desrespeito vinculam uma força moral capaz de promover desenvolvimentos e progressos na vida social e o reconhecimento do sujeito como pessoa de valor (HONNETH, 2003).

Já o quarto aspecto trata das reações emocionais negativas assumirem uma importância fundamental para impulsionar a luta por reconhecimento. As experiências de desrespeito vinculam determinadas reações psíquicas negativas que podem constituir a base motivacional afetiva para a luta por reconhecimento. Portanto, se, por um lado, as experiências de desrespeito como a humilhação e a exclusão ameaçam a própria integridade ou a identidade dos indivíduos, por outro, podem converter-se no impulso motivacional da luta por reconhecimento. A crítica de Honneth a Hegel e a Mead (2003), a esse respeito, reside no fato de que faltaria neles justamente o elo psíquico que torna possível passar do desrespeito à ação. Tal elo seria o fator que desempenharia o papel de informar cognitivamente à pessoa que experiência o desrespeito sobre a sua situação social (HONNETH, 2003).

Essa função de passar do sofrimento à ação pode ser desempenhada por reações emocionais negativas e são, principalmente, sentimentos como a vergonha e o desprezo que dão a base para um sujeito reconhecer a negação injustificada do reconhecimento social, o que justifica a tese de que para chegar a uma autorrelação bem-sucedida o indivíduo depende do reconhecimento intersubjetivo de suas capacidades e realizações. Se, ao contrário, essa forma de assentimento social não ocorrer em alguma das etapas de seu desenvolvimento, acontecerá de se abrir na personalidade uma espécie de uma lacuna psíquica, entrando reações emocionais negativas nela, como a vergonha e a ira. A abertura de tal lacuna é possível em razão de que a experiência de desrespeito vem sempre acompanhada de sentimentos afetivos, os quais podem indicar ao indivíduo que "determinadas formas de reconhecimento the são socialmente denegadas" (HONNETH, 2003, p. 220). Por conseguinte, é quando as expectativas de reconhecimento profundamente arraigadas são desapontadas que se torna possível desencadear um tipo de experiência moral, expressa por meio do sentimento de desrespeito.

\footnotetext{
${ }^{3}$ A questão das formas de luta pode gerar expectativas de sucesso quanto ao atendimento às demandas pedidas por cada grupo social. Muitas dessas demandas, porém, podem não ser atendidas logo de primeiro momento. 0 que fica em tais lutas é o papel do simbolismo que essas reivindicações possuem em seus conteúdos. Boa parte dos movimentos políticos possui esse simbolismo. Dito de outro modo, o legado a ser deixado por esses grupos que reivindicam diariamente os seus direitos ganha escopo, conteúdo entre os membros de tais movimentos. 0 simbolismo, portanto, está no imaginário das pessoas que militam por dias melhores em suas vidas.
} 
Por fim, o quinto aspecto é a tese de que o estabelecimento de uma relação positiva consigo mesmo associa-se à capacidade do sujeito ser reconhecido como pessoa de valor é tematizada por Honneth (2003), recorrendo à concepção de sentimentos de Dewey (2003), de modo que para Honneth (2003), os sentimentos representam reações afetivas que decorrem do êxito ou não de nossas ações e intenções práticas. Esse ponto de partida auxilia-o a encontrar uma via para distinguir os tipos de perturbações que incidem sobre a ação humana e que são avaliadas pelas expectativas, orientadoras da própria ação, desencadeando conflitos morais na esfera do mundo da vida, compreendidos como infração de normas pressupostas válidas, que se traduzem em sentimentos morais de injustiça.

As diferenças entre as reações emotivas são medidas de acordo com a violação de normas que refreiam a ação. Este refreamento pode advir tanto do próprio sujeito quanto de quem compartilha com ele a interação. No primeiro caso, vivencia-se o contrachoque de suas ações com sentimento de culpa; no segundo, com sentimentos de indignação. De acordo com Honneth (2003), o ponto central vislumbrado por Dewey (2003), nessas experiências de vivência afetiva de ações rechaçadas, reside na tomada de consciência do elemento cognitivo das próprias expectativas, qual seja, o saber moral que conduziu à ação que foi refreada.

Honneth entende que, nas reações emocionais decorrentes da vergonha, as experiências de desrespeito podem adquirir o impulso motivacional necessário para uma luta por reconhecimento. Isso ocorre em razão de que a tensão afetiva gerada ao indivíduo na forma de vergonha e humilhação só pode ser dissolvida na possibilidade efetiva da ação. Dentre os sentimentos morais, Honneth destaca o da vergonha, por possuir o caráter mais aberto e por traduzir-se como uma espécie de rebaixamento do próprio valor do sujeito. Isso ocorre por tratar-se de um sentimento vivenciado "somente na presença de parceiros de interação, reais ou imaginados, aos quais incumbe de certa maneira o papel de testemunha da lesão dos ideais de ego" (HONNETH, 2003, p. 223).

Apesar dessas contribuições, a teoria do reconhecimento em Honneth não se limita a isso. No próximo tópico será abordado quais implicações à teoria de Honneth possuem em relação à formação. Mais precisamente, até que ponto a teoria deste autor implica de fato uma intersubjetividade, e não apenas esse aspecto: quais os pontos interativos que expressam uma mediação.

\section{3-Reconhecimento e Formação: Existe Possibilidade de Interagir entre Conflito e Formação em Honneth?}

Verifica-se que, como impulso, para a luta por reconhecimento, o conflito permite a formação da identidade individual. Tomando essa ideia central como referência, pretendemos explorar, neste momento do argumento, os conceitos de socialização e autorrealização, os quais ajudam a explicitar aspectos importantes do vínculo existente entre conflito e formação, em conformidade com o que diz Honneth.

Atualmente, é variado o espectro das compreensões sobre a socialização, mas Honneth, embora não seja um teórico desse campo no sentido estrito do termo, pode ser situada a partir da 
tradição que compreende socialização como interação. ${ }^{4}$ Sua contribuição a esse respeito situa-se ao destacar o papel das interações voltadas à busca por reconhecimento como resultantes de processos conflitivos motivados pela quebra de expectativas normativas socialmente arraigadas. Cabe, pois, levar em conta, aqui, o conceito de conflito associado a processos de socialização, mas mantendo o seu sentido de fundo, ou seja, a força moral contida em experiências de desrespeito.

É possível compreender a formação da identidade humana como um fenômeno que, em razão de sua natureza prática, dificilmente pode ser pensada sem a ideia de conflito, o qual é intrínseco à formação tanto da identidade dos sujeitos singulares quanto dos processos de constituição da intersubjetividade. O próprio Mead (1967) já explicitara isso ao mostrar que o sujeito, muitas vezes, sente o afluxo de normas intersubjetivas oriundas do meio social, tendo que colocar em dúvida seu próprio $M E .^{5}$

Como registra Honneth, "o 'Me' incorpora, em defesa da respectiva coletividade, as normas convencionais que o sujeito procura constantemente ampliar por si mesmo, a fim de poder conferir expressão social à impulsividade e criatividade do seu 'Eu'” (2003, p. 141). 0 atrito entre o I e o Me, entre a identidade pessoal e a identidade social, representa o conflito fundamental para explicar o desenvolvimento moral tanto dos indivíduos quanto da sociedade. A se compreender os processos de interação como processos de socialização na linha da tradição que remonta a Simmel $(1981 ; 1999)$ e, pois, como dinâmicos e abertos à contingência, pode-se, com alguma facilidade, encontrar aí também o conflito como uma de suas dimensões constitutivas, explícitas.

O que há em comum entre autores como Simmel (1981;1999), Mead (1967) e Habermas (2003) são a ideia de que os processos de socialização estão diretamente vinculados às interações humanas. É mediante tais processos que a identidade dos indivíduos se configura, o que não ocorre de maneira linear. A contribuição importante de Honneth a esta tradição é a introdução do tema do conflito como central para a compreensão das interações sociais e da formação da identidade humana, bem como para o desencadeamento de ações emancipatórias.

Isso é levado adiante, como vimos, pela ideia de que, quando o indivíduo vivencia experiências de negação de reconhecimento em qualquer um dos três padrões sugeridos, são afetados aspectos constitutivos de sua própria identidade, o que pode gerar consequências drásticas para o êxito dos processos de socialização e para os processos educativos em sentido mais específico. A teoria do reconhecimento proposta pelo filósofo frankfurtiano coloca, no centro do debate político, a tensão entre conflito e reconhecimento. Nessa tensão, as experiências de desrespeito são reinterpretadas a tal ponto que se efetiva/manifesta a identidade do sujeito. Identidade essa estruturada, fundamentalmente, a partir de interações intersubjetivas.

Ainda é preciso levar em consideração que tal estrutura advém de processos de socialização e que, nas experiências de desrespeito, tais processos são prejudicados. Ambientes educativos são

\footnotetext{
4 Um bom panorama sobre essa tradição pode ser encontrado em Grigorowitschs (2010).

5 A expressão inglesa me, que significa a mim mesmo, possui uma conotação de análise das próprias mediações internas e externas da construção da personalidade do sujeito. A referida expressão é bastante utilizada em diversas áreas de conhecimento: psicologia, ciências sociais entre outros. Na filosofia, me adquire uma relevância ainda maior pelo fato da análise das possíveis implicações cognitivas, sociais ou políticas deste sujeito perante a consigo mesmo e aos demais ao seu redor.
} 
perpassados pelas interações que permeiam o conjunto do tecido social, ficando, pois, vulneráveis às experiências, inclusive de desrespeito, as quais são advindas do âmbito social, violadas de expectativas normativas, ancoradas em seu contexto interno de interação. Vale ressaltar que, para Honneth, o conflito decorre da violação de expectativas de reconhecimento enraizadas nas relações intersubjetivas. São essas expectativas subjacentes aos processos de formação da identidade que permitem ao sujeito, como também ao estudante, compreender-se como ser autônomo e independente. Instituições educativas, concebidas como instâncias socializadoras que são, ficariam ameaçadas em seu papel formativo quando afetadas as condições para o estabelecimento de uma relação positiva dos sujeitos para si próprios e, pois, seu acesso à autonomia. Como destaca Voirol (2008):

A expectativa de reconhecimento não preenchida supõe uma perturbação do processo intersubjetivo da construção de si e faz com que os atores, ao se verem como vítimas da negação do reconhecimento no processo intersubjetivo de socialização, se revelem pouco dispostos à autonomia do juízo e à afirmação de uma dinâmica pública de argumentação (VOIROL, 2008, p. 51).

Honneth (2006) frisa que "a socialização dos seres humanos só pode ser bem-sucedida sob condições de liberdade cooperativa" (HONNETH, 2006a, p. 110). Em outros termos, a autorrealização individual só é possível quando combinada com a dos demais membros da sociedade por meio de princípios ou fins aceitos por todos. Nesse sentido, observa ainda, na esteira de Hegel e de Adorno, que "somente pode haver formas bem-sucedidas de socialização onde forem estabelecidos modos de ação em comum que possam valer como metas racionais de autorrealização desde a perspectiva de todos os sujeitos individuais" (HONNETH, 2007, p. 111).

O filósofo frankfurtiano vale-se da ideia de que as expectativas normativas dos sujeitos estão orientadas para o "reconhecimento social de suas capacidades por outros diversos outros generalizados” (2007, p. 120). Essa posição, portanto, implica uma concepção de socialização moral do sujeito em que a formação da identidade individual acontece através de etapas de interiorização de respostas de reconhecimento "socialmente estandarizadas", ou seja, reconhecendo um valor implícito que antes não imaginaria possuir. Isso significa, nesse sentido, que "os indivíduos aprendem a verem-se a si mesmos como membros plenos e especiais da comunidade ao ir gradualmente se assegurando das capacidades e necessidades específicas que os constituem como personalidades mediante a reação de apoio de seus parceiros generalizados de interação" (HONNETH, 2007, p. 123).

Por essa razão, os sujeitos dependem de um contexto de formas de interação social orientado por princípios normativos de reconhecimento mútuo. Quando essas relações de reconhecimento deixam de existir, elas cedem lugar a experiências de falta de respeito ou humilhação que deixam consequências lesivas para a formação da identidade do indivíduo. 0 autor contemporâneo, neste debate, ampara-se num pressuposto ético fundamental de sua teoria do reconhecimento, qual seja: "dos membros de uma sociedade deve poder dizer-se que eles poderão levar em comum uma vida bem-sucedida e não-deformada, somente, se todos eles se orientarem em função de princípios ou instituições que eles mesmos possam compreender como metas racionais de sua autorrealização" (HONNETH, 2007, p. 107). 
Diante do exposto, questionamos: Na contemporaneidade, é possível conceber uma pedagogia do reconhecimento? De acordo com a tese defendida por Honneth (2003), isso é possível. Tal possibilidade existe na medida em que se exige ir além das premissas individualistas do liberalismo, pois demandaria levar em conta o princípio da liberdade cooperativa de modo a entender as relações pedagógicas como normativamente orientadas por tal princípio.

A teoria do reconhecimento distingue-se do liberalismo justamente por um perfeccionismo ético de caráter muito peculiar, a saber, que a meta normativa da sociedade deve consistir em tornar a autorrealização mutuamente possível. Todavia, esta meta deve ser concebida como processo de formação do ser humano (HONNETH, 2006a). A formação do eu prático vincula-se diretamente à possibilidade do estabelecimento de relações de reconhecimento recíproco entre sujeitos, uma vez que é somente quando os indivíduos se veem confirmados em sua autonomia pelos demais que podem chegar a uma compreensão de si mesmos na condição de "um Eu autonomamente agente e individuado" (HONNETH, 2003, p. 120). Baseado nos estudos de Mead (1967), Honneth vincula a ideia de que um sujeito só pode adquirir a consciência de si mesmo na medida em que aprender a perceber a sua própria ação simbolicamente representada a partir da perspectiva de uma segunda pessoa. Ao princípio do reconhecimento é claramente vinculado um papel formativo, visto que a busca de autorrealização é concebida como resultado de um processo de autoconstituição intersubjetiva do ser humano.

$\mathrm{Na}$ base de tal processo, está o conflito como modo de impulsionar o sujeito à formação prática de sua identidade. Essa pretensão de reconhecimento, que permite constituir a identidade humana, é inerente à vida social e traduz-se na forma de uma tensão entre sujeitos que depende socialmente uns dos outros.

Esse processo conflitivo de formação demanda a experiência do reconhecimento que só será possível se o sujeito constituir uma relação positiva consigo mesmo mediante a relação com os outros. Afirma Honneth (2003): “os indivíduos se constituem como pessoas unicamente porque, da perspectiva dos outros que assentem ou encorajam, aprendem a se referir a si mesmos como seres a quem cabem determinadas propriedades e capacidades" (HONNETH, 2003, p. 272). Sem o desenvolvimento delas não seria possível haver êxito na autorrealização, a qual depende da realização espontânea de metas de vida escolhidas de modo autônomo.

Por conseguinte, para Honneth, assim como para Hegel, uma formação bem-sucedida da própria identidade implica determinadas condições para a autorrealização do indivíduo e está só pode ser exitosa se for unida com a autorrealização de os demais sujeitos em face de princípios ou fins racionais capazes de serem aceitos desde a perspectiva de todos e de cada um. 0 desvio dessa meta é gerador de patologias sociais porque implica a perda da autorrealização em sentido intersubjetivo.

\section{4-Conclusão}

Diante dos argumentos apresentados neste artigo, percebe-se que o tema reconhecimento não é algo descartável, ou simplesmente sem importância para a filosofia, sobretudo, a importância e relevância da filosofia hegeliana no século XX, a qual foi retomada de modo substancial por Axel 
Honneth. A questão central na tentativa de Honneth de reatualizar a filosofia hegeliana é que esta se mostrou insuficiente às demandas da época em que o filósofo da eticidade vivera. Dito de outro modo, novos parâmetros conceituais foram necessários para que a filosofia hegeliana tivesse um propósito mais relevante, uma espécie de "fôlego novo" ao seu sistema filosófico. Este fôlego encontrou-se mais plausível na teoria do reconhecimento de Honneth, tendo em vista que foram encontrados elementos para repensar a teoria hegeliana da eticidade, reescrevendo-a num quadro intersubjetivo em que o reconhecimento, antes restrito a uma estrutura reflexiva, adquire um novo significado. Apesar desses problemas, a intenção de Hegel em tratar o reconhecimento é bastante válida e significativa.

Além disso, a teoria do reconhecimento honneteano pode implicar em uma concepção de vida boa, baseada na orientação dos objetivos da autorrealização humana e, ao mesmo tempo, necessária para guiar-se por normas universais orientadoras da ação, unificando as determinações formais da vida boa aos contextos e às formas de vida particulares - o denominado universalismo contextualista (HONNETH, 2009). Em decorrência disto, as condições intersubjetivas para que a autorrealização e a integridade pessoal sejam asseguradas dependem do grau de desenvolvimento das relações de reconhecimento historicamente constituídas. A abordagem de Honneth, nesse sentido, vai além de Kant porque o seu objetivo não é tratar somente da autonomia moral, mas também das condições de autorrealização do ser humano como um todo. Portanto, tal conceito pretende ampliar a moralidade "no sentido de integrar num mesmo quadro tanto a universalidade do reconhecimento jurídico moral da autonomia individual quanto à particularidade do reconhecimento ético da autorrealização pessoal" (WERLE; MELO, 2007, p. 16).

A autonomia do sujeito, entendido como liberdade de autorrealização, depende de determinados pressupostos, haja vista que ela só pode ser adquirida com seus parceiros de interação. Por essa razão, Honneth (2003) entende que os diferentes padrões de reconhecimento representam condições intersubjetivas e são apresentados como necessários para "descrever as estruturas universais de uma vida bem-sucedida" (HONNETH, 2003, p. 273). Os três padrões de reconhecimento - amor, direito e solidariedade- são considerados como condições para a autorrealização e são suficientemente formais para não incorporarem ideais de vida específicos. Por outro lado, são ricos em termos de conteúdo a ponto de irem além, no que se refere às estruturas universais de uma vida bem-sucedida, da referência apenas à autodeterminação individual.

A partir do exposto e de outras discussões a serem inseridas futuramente em outros textos, reafirma-se a relevância de discutir o papel do reconhecimento na filosofia. Uma teoria do reconhecimento que vincule uma concepção pós-metafísica de vida boa deve valer-se de padrões suficientemente formais para deixar, em aberto aos indivíduos, distintas opções de autorrealização e, pois, de formação de suas identidades. A teoria do reconhecimento de Honneth (2003) contém um rico potencial teórico a ser explorado em relação a diversas áreas: filosofia política, ética etc. 
O papel do conflito na teoria crítica contemporânea em Axel Honneth

\section{Referências Bibliográficas}

HONNETH, Axel. Dilemmas of Justice in a 'Postsocialist' Age. In: Justice Interruptus - critical reflections on the 'postsocialist'condition. London: Routledge, p.11-39, 1997 [1995].

Rethinking the Public Sphere: a contribution to the critique of actually existing democracy. In: DURING, Simon (ed.). The Cultural Studies Reader. Londres: Routledge, p. 518-536, 1999.

Rethinking recognition. In: New Left Review (II), 3, p.107-120, 2000.

Recognition without ethics? In: Theory, Culture \& Society. Londres / Thousand Oaks / New Delhi, v. 18, n. 2-3, p. 21-42, 2001.

Luta por reconhecimento: A gramática moral dos conflitos sociais. Trad. Luiz Repa. São Paulo: Ed. 34, 2003a.

Social Justice in the age of identity politics: Redistribution, Recognition, and Participation. In: FRASER, N; HONNETH, A. Redistribution or Recognition. A political- Philosophical exchange. Londres/Nova York: Verso, p. 07- 109, 2003b.

. "Distorted Beyond All Recognition: A Rejoinder to Axel Honneth". In: FRASER; HONNETH. Redistribution or recognition: a political-philosophical exchange. London: Verso, 2003c.

Reconhecimento sem Ética? Lua Nova, São Paulo, n. 70, [2001] 2007, p. 101-138.

- "Social Justice in the Age of Identity Politics: Redistribution, Recognition, and Participation”. In: FRASER; HONNETH. Redistribution or recognition: a political philosophical exchange. London: Verso, 2009.

VOIROL, Olivier. - A esfera pública e as lutas por reconhecimento: De Habermas a Honneth. In: Cadernos de Filosofia Alemã, n.11, Jan-Jun 2008, p.33-56.

WERLE, D. L.; SOARES MELO, R. Introdução: Teoria crítica, teorias da justice e reatualização de Hegel. In: HONNETH, A. Sofrimento de Indeterminação. São Paulo: Esfera pública, 2007, pp. 7-44. 